\title{
Our experience in Costa Rica on treatment of disc herniation
} [abstract]

\author{
Carlos A. Contreras', Humberto Trejos², Verne Lizano1 \\ ${ }^{1}$ Clinica Biblica Hospital, San Jose, Costa Rica, ${ }^{2}$ Cima San Jose Hospital, San Jose, Costa Rica.
}

\section{ABSTRACT}

\section{วิ OPEN ACCESS}

\section{Citation}

Contreras CA, Trejos H, Lozano V. Our experience in Costa Rica on treatment of disc herniation [abstract]. Proceedings of The World Conference on Ozone Therapy in Medicine, Dentistry and Veterinary. Ancona (Italy). September 22nd - 23rd - 24th , 2017. J Ozone Ther. 2019;3(4):11. doi: 10.7203/jo3t.3.4.2019.15401

Academic Editor

Jose Baeza-Noci,

School of Medicine, Valencia

University, SPAIN

\section{Editor}

World Federation of Ozone Therapy, Bolgna, ITALY

\section{Received}

June 17, 2019

Accepted

December 08, 2019

Published

December 30, 2019

\section{Intellectual Property}

Carlos A. Contreras.

This is an open access article distributed under the terms of the Creative Commons Attribution License (CC BY 4.0), which permits unrestricted use, distribution, and reproduction in any medium, provided the original author and source are credited.

\section{Author Information}

Email: cacondam@racsa.co.cr
Purpose: To inform on the characteristics, results and epidemiological data on the treatment of Disc Herniation in Costa Rica.

Patients and methods: We evaluated the handling of 1240 patients, with Disc Herniation at Cervical 147 cases (11.85\%), Thoracic 1 case $(0.09 \%)$ and Lumbar 1092 cases (88.06\%) levels. They were all treated with OxygenOzone therapy, in an ambulatory form, with a protocol of treatment, initially consistent of three to four sessions of paravertebral intramuscular infiltration (O3: $20 \mathrm{mcgr} / \mathrm{mL}$ ), followed by a session of "Discolysis" (O3: $38-40 \mathrm{ug} / \mathrm{mL}$ ) technique under sedation and fluoroscopy, followed by four to five complementary sessions of paravertebral intramuscular infiltration of $02-03$, in a lapse from three to six weeks.

Results: In our casuistry we treated 669 men (54\%) and 571women (46\%) and deducted that there is an evident predominance in the incidence of lumbar disc hernias with 1092 cases, followed by the cervical disc hernias with 147cases, with a negligible incidence of Thoracic Hernias (1 case $0.09 \%)$.

Discussion and Conclusion: The results achieved with the O2-O3 Therapy are highly satisfactory; especially with the cervical (84.2\%), and we believe that it is due to a less incidence of associated pathologies and a higher conscience of the problem by the patients. 